\title{
Application of Bokashi, Vermicompost, and Residue of Coffee Testa Bioconversion by Black Soldier Fly (Hermetia illucens) on the Production of Japanese Cucumber (Luffa acutangula)
}

\author{
Ramadhani Eka Putra ${ }^{1 *}$ Rilvi Abilia Tesa ${ }^{1}$ Mia Rosmiati ${ }^{1}$ Angga Dwiartama ${ }^{1 *}$ \\ ${ }^{I}$ School of Life Sciences and Technology, Bandung Institute of Technology \\ *Corresponding author. Email: angga@sith.itb.ac.id
}

\begin{abstract}
Japanese cucumber (Cucumis sativus) is one of the high-value crops cultivated by farmers at small farms in Sumedang, West Java. The preferences of the customer to health and organic cucumber encourage the development of an organic cultivation system for this crop. One of the most important components of crop production is fertilizer. In this study, three types of organic fertilizers (1) bokashi, (2) vermicompost, and (3) coffee testa that was composted by application of black soldier fly (Hermetia illucens) as a decomposer. The growth parameters (plant height and leaves number), harvest (number and weight of fruits), and productivity efficiency (calculated by mass and energy balance) of application of organic fertilizer compared to the control group (only soil). The cucumber was planted in a polybag filled with a $4.5 \mathrm{~kg}$ growth medium ( $3 \mathrm{~kg}$ soil and 1.5 $\mathrm{kg}$ organic fertilizer for treatment groups and full soil for control). The result showed vermicompost group has the best growth parameter and harvest. On the other hand, the control group had slightly higher production efficiency than other groups, the possible factors that affect the production will be discussed.
\end{abstract}

Keywords: Bioconversion, Japanese cucumber, organic fertilizer, production

\section{INTRODUCTION}

Japanese cucumber (Luffa acutangular) is one of the premium horticulture products cultivated in the West Java area. However, the production of this commodity highly depends on the energy input from outside of the system, such as synthetic fertilizer. This condition leads to increased production cost which causes a heavy burden for the smallholder farmer, a dominant farmer group in West Java.

Developing new production practices to reduce the production cost burden for smallholder farmers is of great interest. Among various possible strategies, there is increasing interest in the potential application of organic fertilizer as plant growth media and soil amendments $[1,2]$. Furtherly, fertilizer originated from livestock, agricultural, and municipal waste management gain more interest. There are three types of these fertilizers, which are [1] Bokashi which originated from the fermentation process of livestock manure, [2] vermicompost which produced from the decomposition process of manure through the interaction of earthworms and microorganism, and [3] insect frass which is the residue of organic waste bioconversion process by insect larvae. Studies already reported the benefit of these fertilizers for the improvement of soil conditions for crops [3-5].

The study aimed to investigate the effect of the application of each of these organic fertilizers on the growth and harvest quality of the Japanese cucumber.

\section{MATERIALS AND METHODS}

\subsection{Material}

In this study, 48 seedlings of Japanese cucumber var. Tosca F1 was used as a study subject. There were three types of fertilizers applied in this study, such as (1) Vermicompost) originated from cow's manure, (2) Bokashi, and (3) Residue of coffee testa from bioconversion process by black soldier fly larvae.

\subsection{Method}

Complete random sampling was applied for this study with 4 groups ( 1 control and 3 application groups) 
and 12 repetitions. The groups were consisted of: P1 $=$ control (only soil as growth medium); $\mathrm{P} 2=3 \mathrm{~kg}$ soil $+1,5 \mathrm{~kg}$ bokashi as growth medium; $\mathrm{P} 3=3 \mathrm{~kg}$ soil $+1,5 \mathrm{~kg}$ vermicompost as growth medium; and $\mathrm{P} 4=3 \mathrm{~kg}$ soil $+1,5 \mathrm{~kg} \mathrm{BSF}$ residue as growth medium (compost produced from bioconversion of coffee testa by black soldier fly larvae).

Before the study, the basic nutrient of each growth medium was analyzed in Laboratorium Kimia Tanah dan Nutrisi Tanaman Universitas Padjajaran. The result showed in Table 1

Table 1. Nutrient of growth medium used in this study

\begin{tabular}{|l|l|l|l|l|}
\hline Nutrient & P1 & P2 & P3 & P4 \\
\hline N-Total (\%) & 0.2 & 0.8 & 0.71 & 0.46 \\
\hline $\begin{array}{l}\mathrm{P}_{2} \mathrm{O}_{5} \mathrm{HCl} \\
25 \% \\
(\mathrm{mg} / 100 \mathrm{~g})\end{array}$ & 30.63 & 113.3 & 100.83 & 66.33 \\
\hline $\begin{array}{l}\mathrm{P}_{2} \mathrm{O}_{5}(\mathrm{Olsen}) \\
(\mathrm{ppm} \mathrm{P)}\end{array}$ & 7.99 & 97.07 & 72.88 & 24.85 \\
\hline $\begin{array}{l}\mathrm{K}_{2} \mathrm{O} \mathrm{HCl} \\
25 \% \\
(\mathrm{mg} / 100 \mathrm{~g})\end{array}$ & 48.91 & 76.66 & 69.88 & \\
\hline $\begin{array}{l}\mathrm{C}-\text { organic } \\
(\%)\end{array}$ & 1.89 & 10.12 & 9.93 & 3.85 \\
\hline $\mathrm{pH}$ & 7.96 & 7.81 & 7.38 & 8.43 \\
\hline $\begin{array}{l}\mathrm{CEC} \\
(\mathrm{cmol} / \mathrm{kg})\end{array}$ & 25.41 & 40.14 & 42.97 & 26.41 \\
\hline C/N Ratio & 9 & 13 & 14 & 8 \\
\hline
\end{tabular}

Each growth medium was kept inside a polybag $(30 \times 40 \mathrm{~cm})$ individually. In total, there were 48 polybags used in this study. Cucumber seedling with three leaves was planted in the polybag and cultivated until all plants died.

\subsection{Data collection}

Data collected in this study were (1) plant height, (2) number of leaves, (3) number of male flowers, (4) number of female flowers, (5) total fruit numbers, (6) average fruit weight, (7) average fruit length, and (8) average fruit diameter. Data were collected every 3 days until all fruit produced and mature.

\subsection{Data analysis}

All collected data was subject to statistical analysis. The differences in the variance among data were calculated by ANOVA with a confidence level of $95 \%$. All calculation was conducted by a macro program of Microsoft Excell.

\section{RESULTS AND DISCUSSION}

\subsection{Plant height}

All plants that received organic fertilizer were significantly taller than the control group with the vermicompost group had the highest height $(256 \mathrm{~cm})$ (Fig. 1).

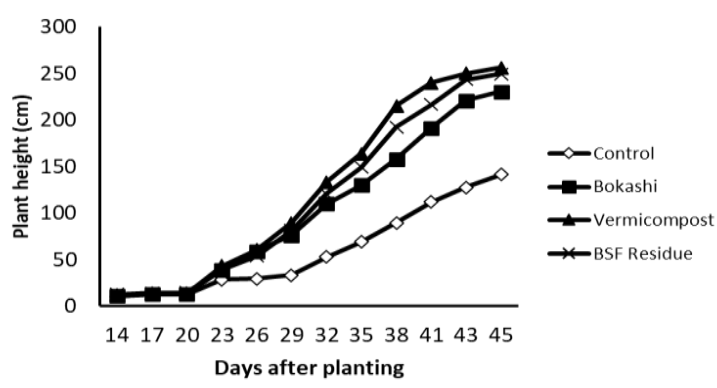

Figure 1. Height of plant received different types of organic fertilizer

This result showed the benefit of the vermicompost to the growth of the plant which was reported in various plants [2]. The improvement of the height could be caused by an increasing amount of auxin which could be found in vermicompost $[6,7]$.

\subsection{Leaf numbers}

The vermicompost group had the highest number of leaves compared with other groups although at the end of observation the average amount of leaf per plant was similar to the bokashi group (Fig. 2).

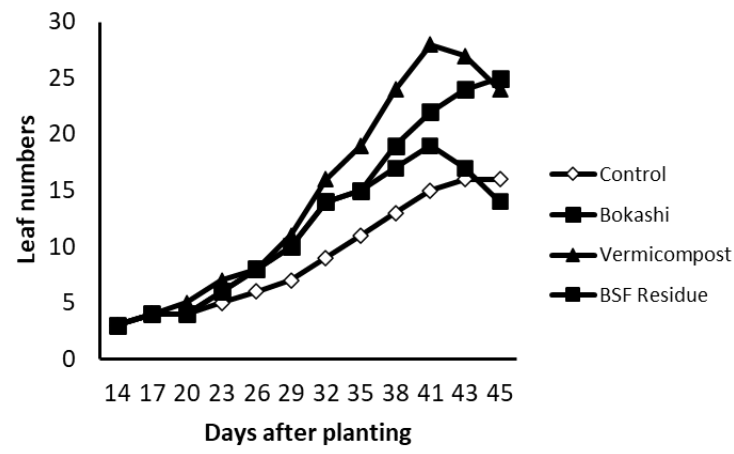

Figure 2. Leaf numbers of the plant received different types of organic fertilizer

The benefit of vermicompost for improving the number of leaves in cucumber also reported by various studies [2,8]. A higher number of leaves for both vermicompost and bokashi group may be related to the level of nitrogen content which higher compared to BSF residue and control. High nitrogen 
levels showed a positive effect on the leaves production in cucumber [9].

An increasing number of leaves may improve the photosynthesis and amount of photosynthate produced by the plant which may improve the quality of the plant products.

\subsection{Number of male and female flowers}

In general, all plants that received organic fertilizer showed significantly higher numbers of male flowers than the control group. Among fertilized groups, the plant that received vermicompost (average number of male flowers produced per plant was 9 flowers) produced more flowers per plant (Fig. 3). There was a similarity in the pattern of male flower production as the highest production level reached between day 38 and 41 for all groups.

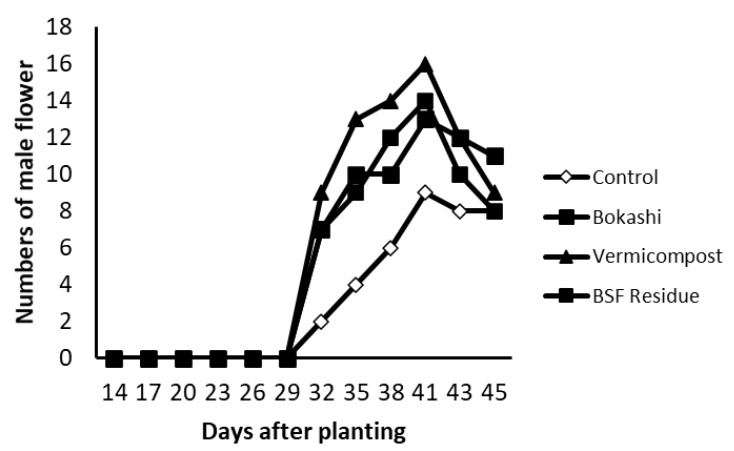

Figure 3. Average male flower numbers per plant of the plant received different types of organic fertilizer.

On the other hand, only vermicompost, bokashi, and BSF residue group (albeit only one flower on the final observation day for BSF group) (Fig. 4). Among these groups, vermicompost produced a significantly higher number of female flowers (the average number of flowers produced was 2 flowers).

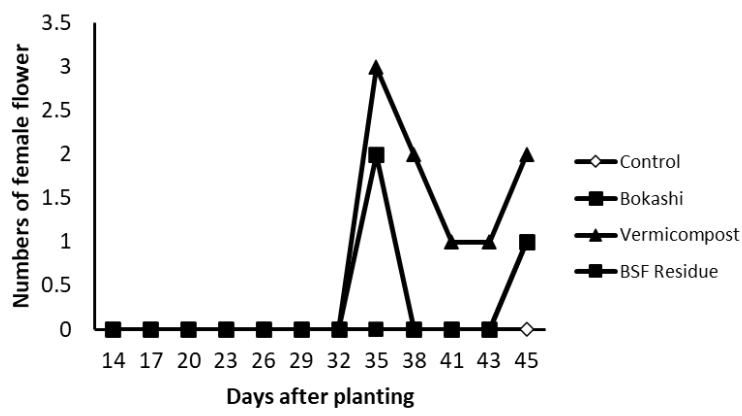

Figure 4. Average female flower numbers per plant of the plant received different types of organic fertilizer.
There was a similarity in the positive effect of the application of vermicompost and bokashi to the production of flowers although the effect of vermicompost was much stronger. The positive effect of vermicompost on flowering was also reported in various plants and crops $[10,11]$. This positive effect may be related to the enhancement of nutrient uptake by the plant [12] and the availability of some plant hormones, like gibberellins, auxin, and cytokinin, in the growth medium which encourages flower production $[13,14]$.

\subsection{Number of fruits}

Plants that received organic fertilizer produced fruits while no fruit was produced for the control group. Vermicompost group produced more fruit than other groups although the number not significantly different from the bokashi group (Fig. 5).

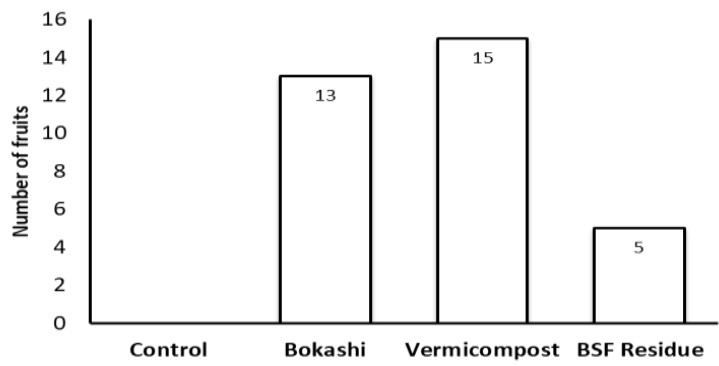

Figure 5. A total number of fruits produced for each study group.

The higher number produced by the vermicompost group could be related to the number of flowers produced. There is a positive correlation between flower numbers and fruit numbers as fruit originated from the flower.

\subsection{Fruit weight}

The average weight of the fruits produced by the vermicompost group was higher than others although the differences among groups were not significant (Fig. 6).

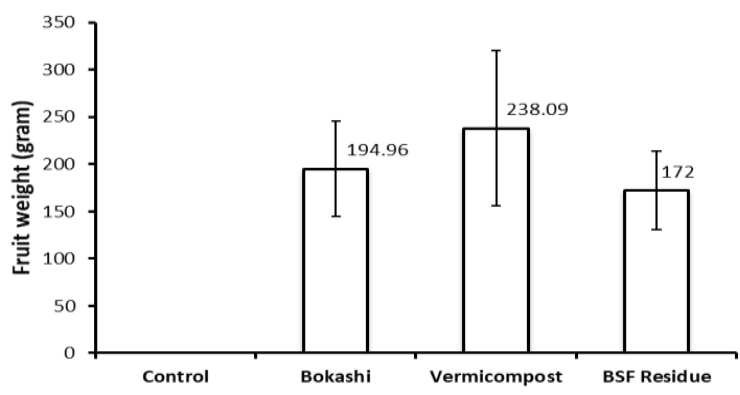

Figure 6. The average weight of fruits produced for each study group. 


\subsection{Fruit length}

There was no significant effect on fruit length detected among application groups although the vermicompost group produced slightly longer fruit than others (Fig. 7).

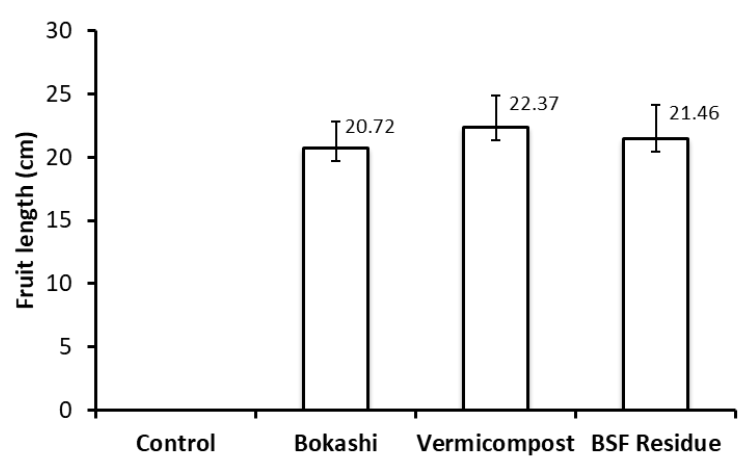

Figure 7. The average length of the fruits produced for each study group.

\subsection{Fruit diameter}

The vermicompost group produced bigger fruit than other groups but not significantly bigger than others (Fig. 8).

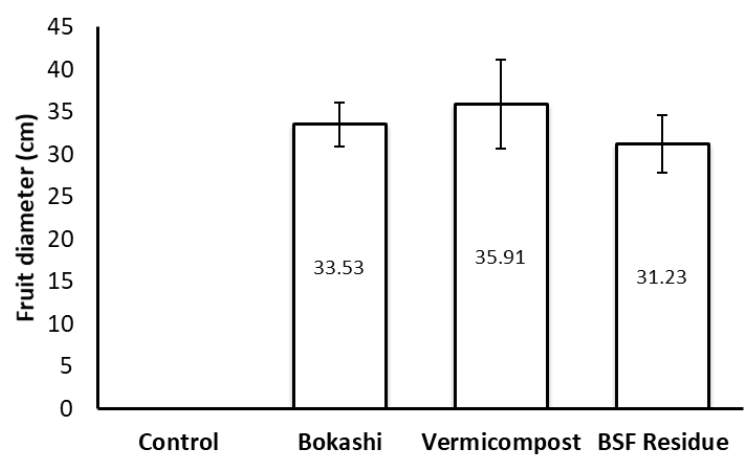

Figure 8. The average diameter of the fruits produced for each study group.

In terms of harvest quality, the quality of the harvested product of bokashi was slightly better than the vermicompost group. It may be related to the availability of more varied microorganisms in the bokashi. Diverse microorganisms may lead to [1] increase enzymatic activity which allows more macronutrients available for plants and [2] enhance the growth of root structure that reflects the ability of plants to resist water stress conditions [15]

\section{CONCLUSION}

The application of organic fertilizer improves the growth and quality of the harvested products of the
Japanese cucumber. Although the effect of BSF residue on the growth and harvest quality of Japanese cucumber lower than bokashi and vermicompost, the differences was insignificant. This indicated the potency of BSF residue as an alternative to solid organic fertilizer. More studies are required to implement this method on the open field condition where the interaction with the environment condition more complex.

\section{ACKNOWLEDGMENT}

This study was partially funded by Program Pengabdian Masyarakat ITB Citarum Harum 2020 granted to the first author.

\section{REFERENCES}

[1] G. Sallaku, I. Babaj, S. Kaciu, A. Balliu, The influence of vermicompost on plant growth characteristics of cucumber (Cucumis sativus L.) seedlings under saline conditions, Journal of Food Agriculture and Environment 7(3\&4) (2009) 869-872.

[2] M. Jandhagi, M.R. Hasandokht, V. Abdossi, P. Moradi, The effect of chicken manure tea and vermicompost on some quantitative and qualitative parameters of seedling and mature greenhouse cucumber, Journal of Applied Biology \& Biotechnology 8(1) (2020) 33-37. DOI: https://doi.org/10.7324/JABB.2020.80106

[3] S. Xiaohou, T. Min, J. Ping, C. Weiling, Effect of EM Bokashi application on control of secondary soil salinization, Water Science Engineering 1(4) (2008) 99-106. DOI: https://doi.org/10.3882/j.issn.16742370.2008.04.011

[4] H.T. Zhao, T.P. Li, Y. Zhang, J. Hu, Y.C. Bai, Y.H. Shan, F. Ke, Effects of vermicompost amendment as a basal fertilizer on soil properties and cucumber yield and quality under continuous cropping conditions in a greenhouse, Journal of Soil and Sediment 17 (2017) 27182730. DOI: https://doi.org/10.1007/s11368-0171744-y

[5] D. Houben, G. Daoulas, M.P. Faucon, A.M. Dulaurent, Potential use of mealworm frass as a fertilizer: Impact on crop growth and soil properties, Scientific Reports 10 (2020) 4659. DOI: https://doi.org/10.1038/s41598-02061765-x

[6] N. Arancon, C. Edwards, R. Dick, L. Dick, Vermicompost tea production and plant growth impacts, BioCycle 48 (2007) 51-52. 
[7] P.R. Warman, M.J. Anglopez, Vermicompost derived from different feedstocks as a plant growth medium, Bioresource Technology 101 (2010) 4479-4483. DOI: https://doi.org/10.1016/j.biortech.2010.01.098

[8] R. Azarmi, M.T. Giglou, B. Hajieghrari, The effect of sheep-manure vermicompost on quantitative and qualitative properties of cucumber (Cucumis sativus L.) grown in the greenhouse, African Journal of Biotechnology 8(19) (2009) 4953-4957. DOI: https://doi.org/10.4314/ajb.v8i19.65198

[9] S. Watcharasak, T. Thammasak, Effect of nitrogen and potassium concentration in fertigation on growth and yield of cucumber, Kamphaengsaen Academic Journal 3 (2005) 1829.

[10] R. Gupta, A. Yadav, V.K. Garg, Influence of vermicompost application in potting media on growth and flowering of marigold crop, International Journal of Recycling of Organic Waste in Agriculture 3 (2014) 47. DOI: https://doi.org/10.1007/s40093-014-0047-1

[11] S.G.P. Kist, M. Joseila, M.R. Matos, S.C. Witt, M.E. Luiz, S.R. Bemfica, O.F.B. Dias, The vermicompost anticipates flowering and increases tomato productivity, Agrociencia Uruguay 23(1) (2019) 1-7.

[12] R. Dinesh, V. Srinivasan, S. Hamza, A. Manjusha, Short-term incorporation of organic manures and biofertilizers influences biochemical and microbial characteristics of soils under an annual crop [Turmeric (Curcuma longa L.)], Bioresource Technology 101(12) (2010) 4697-4702. DOI: https://doi.org/10.1016/j.biortech.2010.01.108

[13] S. Suthar, Evidence of plant hormone like substances in vermiwash: An ecologically safe option of synthetic chemicals for sustainable farming, Ecological Engineering.36(8) (2010) 1089-1092.

DOI:

https://doi.org/10.1016/j.ecoleng.2010.04.027

[14] A.O. Aremu, W.A. Stirk, M.G. Kulkarni, D. Tarkowská, V. Turecková, J. Gruz, M. Subrtová, A. Pnèík, O. Novák, K. Doleal, M. Strnad, L.V. Staden, Evidence of phytohormones and phenolic acids variability in garden-wastederived vermicompost leachate, a well-known plant growth stimulant, Plant Growth Regulation 75(2) (2015) 483-492. DOI: https://doi.org/10.1007/s10725-014-0011-0

[15] D.B. Zandonadi, L.P. Canellas, A.R. Façanha, Indolacetic and humic acids induce lateral root development through a concerted plasmalemma and tonoplast $\mathrm{H}+$ pumps activation, Planta. 225(6) (2007) 1583-1595. DOI: https://doi.org/10.1007/s00425-006-0454-2 